\title{
Development of Multi-Oscillating Water Columns as Wave Energy Converters
}

\author{
Simeon Doyle ${ }^{\mathrm{a}}$, George A. Aggidis ${ }^{\mathrm{b}^{*}}$ \\ Lancaster University Renewable Energy Group, Engineering Department, Lancaster, LA1 4YR, United Kingdom, \\ as.doyle1@lancaster.ac.uk, bo.aggidis@lancaster.ac.uk. \\ *Corresponding author. Tel.: +44(0)1524593052. E-mail: g.aggidis@lancaster.ac.uk (G. A. Aggidis).
}

\begin{abstract}
Wave energy development continues to advance in order to capture the immense ocean energy available globally. A large number of wave energy conversion concepts have been developed and researched to date but we are still not able to see a convergence of technologies. This provides the requirement and additional opportunity for further research. This paper provides a review and discusses the development of the OWC concept of wave energy converters in general and the evolved variation of the M-OWC more specifically. The review outlines the increased potential of the M-OWC concept and its current state through its advancement in recent years. Although still under development the M-OWCs have the potential to provide promising results, through the various innovative concepts under consideration, and support the progression and further development of wave energy as another serious contender in the renewables energy mix.
\end{abstract}

\section{Keywords}

Wave Energy Converter, Oscillating Water Column, Ocean Energy, Review, Renewable Energy

\section{Introduction}

The oceans, which cover a majority of the earth's surface, are by far the largest source of renewable energy yet to be harnessed effectively [1]. Even though there are over one thousand wave energy converter (WEC) patents, very few have progressed into development, let alone full-scale demonstration or commercialisation [2].

Although there are aims to increase harnessing of all renewable energy resources and develop more energy efficient systems, world energy consumption is expected to rise by $28 \%$ before 2040 [3], in conjunction with global electricity demand forecasted to rise by $65 \%$, with $85 \%$ of that demand expected to come from developing nations [4].

Ocean waves are formed due to the interaction between strong offshore winds and the ocean surface. Thus, large waves that reach the shoreline have travelled very long distances while suffering minimal energy loss $[5,6]$. Other forms of renewable energies are less power dense than both wave and tidal energy, with a typical $2-3 \mathrm{~kW} / \mathrm{m}^{2}$ across a wave farm compared to an upper value of $0.6 \mathrm{~kW} / \mathrm{m}^{2}$ on wind farms. Furthermore, the lack of consistency and predictability with alternative forms such as wind and solar means that production is only possible for $20-30 \%$ of the 
time in the UK. Wave energy can harvested from up to $90 \%$ of the time, however the diversity of this resource and the challenge of its extraction is more complex $[1,5,7]$.

The oscillating water column (OWC) is a well-established wave energy device concept, which will continue to contribute greatly in the progression of wave energy. The OWC and the associated devices in existence have been well reviewed in literature [5,7-14]. However, there has been much lesser focus on the multi-oscillating water column devices (M-OWCs) in the past $[13,15,16]$, although a specific interest is starting to develop $[17,18]$. This paper aims to fill this gap by firstly discussing the evolution of the OWC concept, then introducing and reviewing the relevant M-OWC technology and devices.

\section{Brief overview of Wave Energy}

\subsection{Wave Energy Resource}

There are many publications of past and ongoing studies into wave energy resource that reveal the potential for both the globe [8, 19-24] and waters local to the UK [25-27]. Both UK and global studies reveal a worldwide wave resource 93,000TWh/year [23]. However, Ref. [8] notes that there is a variance of estimations across literature that suggests there's a need for an accurate database. True resource characterisation is important when considering WEC deployment, as devices are best suited to particular locations due to their characteristics and tuning. For example, damping and natural frequencies, which will allow for optimal extraction of the wave energy available and therefore the resource should be considered from the outset $[8,28]$.

The UK and Western Europe are among the highest with available wave power resource [2]. The UKs potential is between 250-600 TWh/year [8], which is roughly 35\% of Europe's wave energy resource [29]. Vast differences come between these theoretical and practical resource predictions of around $70 \mathrm{Twh} /$ year when considering implications such as marine environmental and industrial interactions [30,31]. Such resource and potential give license to set targets; one being set by the EU to have an ocean energy capacity of $100 \mathrm{GW}$ by 2050 [9, 32, 33]. However, as of the end of 2016, in Europe only 14 MW of ocean energy capacity was installed [10].

\subsection{Wave Energy Device Development}

Wave energy converters can be characterised with several sub-categories. As summarised in Table 1, these categories are; the operational concepts, their locations with respect to the shoreline, their state of buoyancy or water depth positioning and orientation with respect to the incident wave [5, 7, 34]. Further sub-categories exist to characterise WEC operation and the various steps in the wave-to-wire conversion, as well as categories based on biomimetic rules [35]. These alternative devices somewhat cultivate their own sub-category, such as piezo-electric seaweed [36].

There are various databases that list known WEC concepts and devices in development [9, 10,37-40], but true numbers in development are uncertain. The large variety of wave energy devices is due to a lack of convergence in technology, which is necessary in order to overcome such a diverse range of development. Other forms of renewable energies, namely wind, have a much more refined range of devices. The larger variety of WECs at lower levels of development result in steep competition but with no indication of the most ideal technologies for given settings [34]. 
The WEC development process is large and demands major financial support, which requires an attractive investment opportunity to provide a competitive alternative to other fuel based sources. Compared with other forms of renewable energies, despite the density of wave energy, the returns are not significant enough to provide enough incentive to overcome the current technical issues to be discussed.

Table 1 - Categories for wave energy device characterisation [5, 7, 34]

\begin{tabular}{cccc}
\hline Operational concept & Location & State & Orientation \\
\hline Wave Activated Body & Onshore & Fixed & Attenuator \\
Oscillating Water Column (OWC) & Nearshore & Floating & Terminator \\
Overtopping & Offshore & Submerged & Point Absorber \\
Oscillating Wave Surge Converter (OWSC) & & \\
Rotating Mass & & \\
Pressure Differential & & \\
\hline
\end{tabular}

A large number of concepts fail to surpass early stages of development with very few reaching demonstration or prototype stage [20]. The Technology Readiness Levels (TRLs) and development protocols outline the necessary steps to be taken during WEC development to finish with a viable and attractive deployment proposal [41-44]. In latter stages indexing is complemented by the Commercial Readiness Levels (CRL) index, a financial based protocol [45].

Based on a number of factors, as in Ref. [46], the multi-point absorber and attenuator WECs have the highest deployment attractiveness in the USA and UK respectively. This gives reason to the fact that according to Ref. [2] these devices are the most deployed as seen in Figure 1. Furthermore, development traits have proven that offshore and floating type WECs make up $64 \%$ and $67 \%$ of the development projects respectively [47]. The OWC WECs are found at a combination of locations and water depths, generally, fixed devices are found in intermediate to shallow waters and floating in deeper waters [23]. 


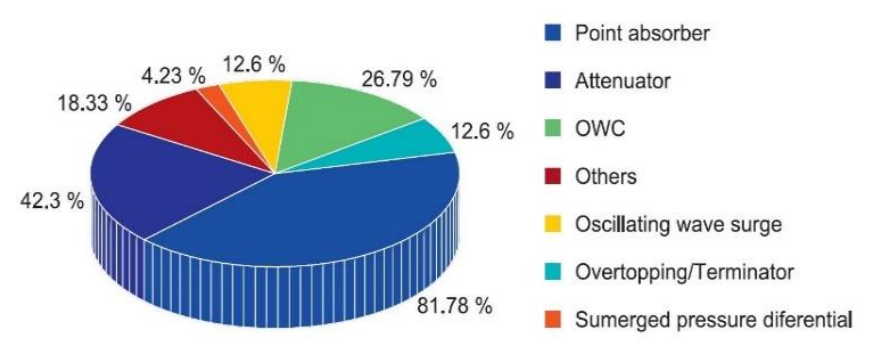

Figure 1 - Wave Energy Converter Deployment [2]

\subsection{Challenges and Barriers}

Issues that affect progression of wave energy as a whole are either technological challenges or economic, social and environmental barriers. Wave energy converter design and especially OWCs face a number of great technological challenges. The major being the irregular and slow $0.1 \mathrm{~Hz}$ wave frequency and behaviour that must transpire to a smooth $50 \mathrm{~Hz}$ at the generator [48]. Methods in achieving steady electrical output include energy storage methods, device arrays or device control [5]. Another significant challenge for the OWC and offshore industries in general is the extreme marine environmental conditions. These inhospitable conditions reinforce requirement for quality structural and material design. Storms result in wave power levels in excess of $2000 \mathrm{~kW} / \mathrm{m}$, which not only raises structural question marks but also will be worthless for power generation as these are infrequent occurrences, which devices aren't tuned for and is therefore as futile as a flat ocean [5].

It is clear that WEC development is the most costly aspect of the lifetime costs of a project, accounting for $22 \%$ of total costs [49]. Installation of a farm therefore, without additional subsidies, makes the comparative capital costs of other energy sources such as fossil, nuclear and majority of renewables more attractive [50]. However, although the initial capital costs are high, without the need for fuel purchase, revenue becomes a function of the energy yield [20].

Aside from technological challenges, these external barriers can be categorised and detailed as by Ref. [51]; Complex planning processes, Administrative procedures, Environmental Impact Assessment process, and Interactions with other marine uses and stakeholders. However, it is expected that as technology converges and development progresses, so will these external barriers as knowledge in general increases. Wave energy is said to have a much lower environmental impact than tidal for example, however, uncertainties still exist with longer term question marks on downstream costal, moorings, cabling and marine life impacts [49]. More than environmental issues, economic and social impacts need to be the focus of these external factors; these include quantifying positive socio-economic impacts and cost-benefit analyses. 


\section{Oscillating-Water-Column Technology}

\subsection{Background}

Yoshio Masuda was the first to implement the OWC concept in fairway and weather buoy with ratings of $70 \mathrm{~W}$ and $120 \mathrm{~W}$ from 1965 in Japan [52]. Masuda later patented the OWC concept and variations in the 1980's [53]. Masuda went on to scale up the OWC concept with a commercial-size device known as Kaimei in Japan (1978), developed by the Japanese Marine Science and Technology Centre (JAMSTEC). The Kaimei originally had 22 OWC chambers and was later reduced to 13 in the second round of sea trials [16]. JAMSTEC continued development at a later date (from 1998) with the trials of the Mighty Whale, a 50m long 3-chamber prototype [54, 55]. Other OWC prototypes were built subsequently, not only in Japan with fixed onshore variations like the shoreline Gully, Sanze, the Offshore Breakwater, Sakata Port, The Kujukuri and Haramachi [56], but also globally, in nations including Norway with the Toftestallen (1985) and India with the Vizhinijam (1990) [11, 57].

\subsubsection{Working Principle}

The OWC concept has been applied worldwide in many different variances, preferred due to its simple operation with no submerged moving parts, structural robustness, ease of maintenance and versatility to be implemented in a wide range of applications.

The basis of the OWC wave-to-wire energy conversion is illustrated Figure 2. The wave-to-wire conversion requires two stages. The first stage being the pneumatic power from hydrodynamic interaction into mechanical, where the energy of the waves pressurises the working fluid, which is utilised by the air turbine or PTO (Power Take-Off). The second stage is then the conversion from mechanical to electrical energy using a generator.

The OWC concept harnesses the energy of a wave by using free-surface movement as a piston and therefore effectively creating a pump. Structures, either floating or fixed have semi-submerged chambers contain a volume of water and air. As depicted in Figure 3 [58], surface elevation occurs as the peak of the wave passes and descends with the trough of the wave causing bidirectional airflow and pressure fluctuations within the chamber, and for a simple OWC concept like this, past the turbine also. In these more common bidirectional airflow systems, a self-rectifying turbine is required to facilitate a constant rotation in one direction while flow is continuously changing direction past the turbine. The Wells turbine, designed by Professor Wells from Queens University, is the most commonly used in OWCs with its variations. A competitor to the Wells turbine was the Australian invention known as the Denniss-Auld

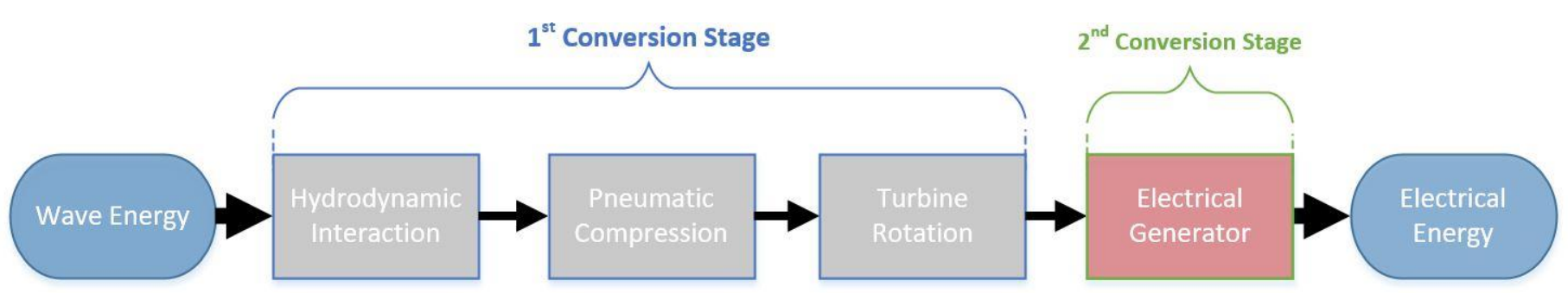

Figure 2 - Oscillating water column wave energy conversion processes (adapted from Ref. [13]) 
turbine, which was later implemented in the Oceanlinx OWCs [15]. Alternative turbine options exist in development, such as the self-rectifying bidirectional impulse turbine [59], and savonious turbine [60].

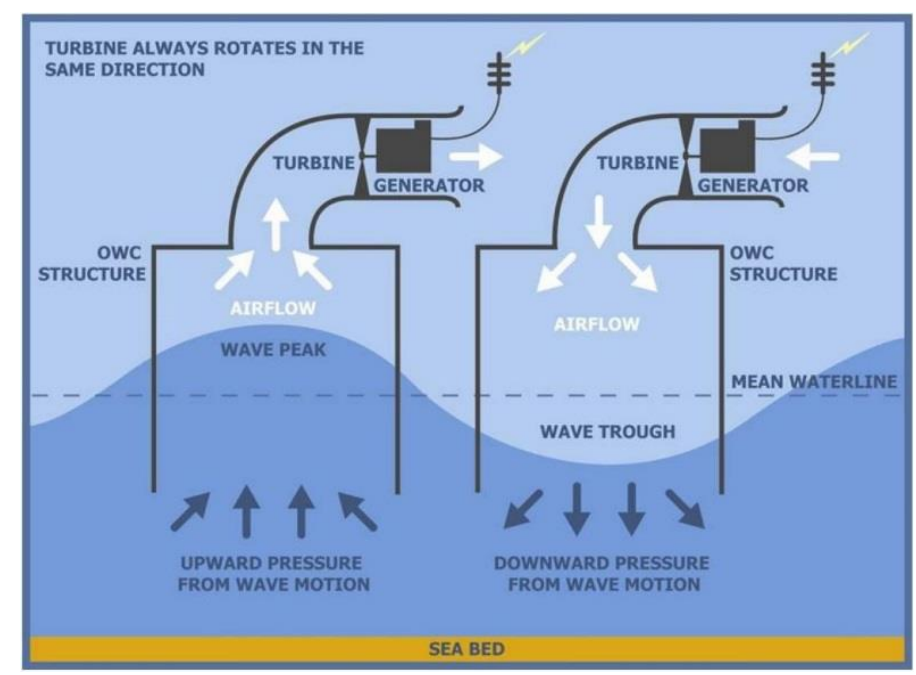

Figure 3 - The oscillating water column concept [58]

\subsubsection{Hydrodynamic Performance and Disadvantages}

Optimisation of the hydrodynamic conversion processes $\left(1^{\text {st }}\right.$ stage $)$ for an OWC is vital since the power available at the PTO is ultimately a function of the pressure differential created by the high pressure up-stream and the air volume flow rate, and thus is dependent on an efficient hydrodynamic process. The optimisation of just this $1^{\text {st }}$ stage may include investigations into the front wall shapes, draft and slope, chamber water plane area shape, PTO orifice or valve sizes, PTO damping, mooring configurations, ballast control and more [61]. This efficiency is generally characterised by the Capture Width Ratio (CWR), which is the ratio between the wave power successfully captured and the re-source of the wave per unit width [38]. A crucial condition in achieving maximum pneumatic power at the turbine is having the device operate as near to the resonance condition as possible. This is attained by the matching natural frequency of the OWC and the heaving frequency or period of the waves [11]. The natural frequency is ultimately determined by the geometrical characteristics of the OWC. Hence, an OWC can be designed to extract energy efficiently when conditions suit and resonance occurs, but outside of this optimal condition operation is less efficient. This is a disadvantage of the raw OWC concept - its inability to tune to varying sea conditions and therefore having a small bandwidth of optimal operation.

A further disadvantage with OWC operation is the varying power output due to bidirectional airflow. Power extraction is made possible with self-rectifying turbines like the previously mentioned Wells Turbine that rotates in the same direction during inhalation and exhalation of the OWC [15]. Although self -rectifying bidirectional turbine technology is improving, it is still an inefficient process in the energy conversion. Furthermore, it has been proven 
that the exhalation process is less efficient than the inhalation. Unidirectional turbines are more efficient and thus single directional flow is more desirable for energy extraction [62].

\subsection{OWC Devices and Development}

Along with the aforementioned original OWCs and their variations, following a decision made by the European Commission in 1991 to include wave energy in the JOULE programme, two onshore pilot OWC plants were constructed. One called the LIMPET (2000), on the Isle of Islay, Scotland, and the Pico Plant (1999), in the Azores, Portugal $[15,63,64]$. In 2001, the Wavegen deployment of LIMPET then became the first wave energy plant to be connected to the grid in the UK. Both plants have facilitated in very useful research and development, for example, the Pico Plant, which was involved in six or more European projects. Following a storm on the $17^{\text {th }}$ of April 2017, the Pico Plant suffered significant structural damage, and due to lack of financial support, WaveEC made the decision to dismantle the plant in 2018 [63]. Currently, the LIMPET still stands despite having faced the largest storms recorded on the Islay [65].

The majority of OWCs have been fixed and usually onshore like the LIMPET, Pico and the more recent plant on Jeju Island (South Korea), which yields opportunities for synergy projects like integration with breakwaters. Examples of synergies such as this is the previously mentioned Vizhinjam in India and in Sakata Port, Japan, and in more recent years the Mutriku in Spain [66-68].

Aside from fixed OWCs mentioned, since floating devices such as the Mighty Whale, predominantly just singular column devices have been considered for offshore deployment. The Oceanlinx, previously known as Energetech, devices (greenWave, ogWAVE, BlueWAVE) are singular OWCs designed for different water depths and wave conditions. A 1 MW prototype of the greenWave device was launched in Australia in 2013, however due to a transportation incident, the deployment was not completed [69, 70]. Worldwide, OWC deployment has seen the failure of a number of other devices destroyed by the harsh marine environment. Devices such as the Toftestallen, Norway; Osprey, Scotland; Pico Plant, Portugal; and the Mutriku in Spain [63, 66, 71].

The popularity and versatility of the OWC concept has led to it being used in a range of devices and applications. For example, as a point absorber type OWC like the Spar Buoy in Figure 4 [15]. This simple, compact and stable floating axisymmetric device contains the OWC inside the length of the body, which features a flare like opening aimed to assist the control the direction of the heave. At the head of the OWC is a vertical axis self-rectifying air turbine that rotates during inhalation and exhalation [11]. 

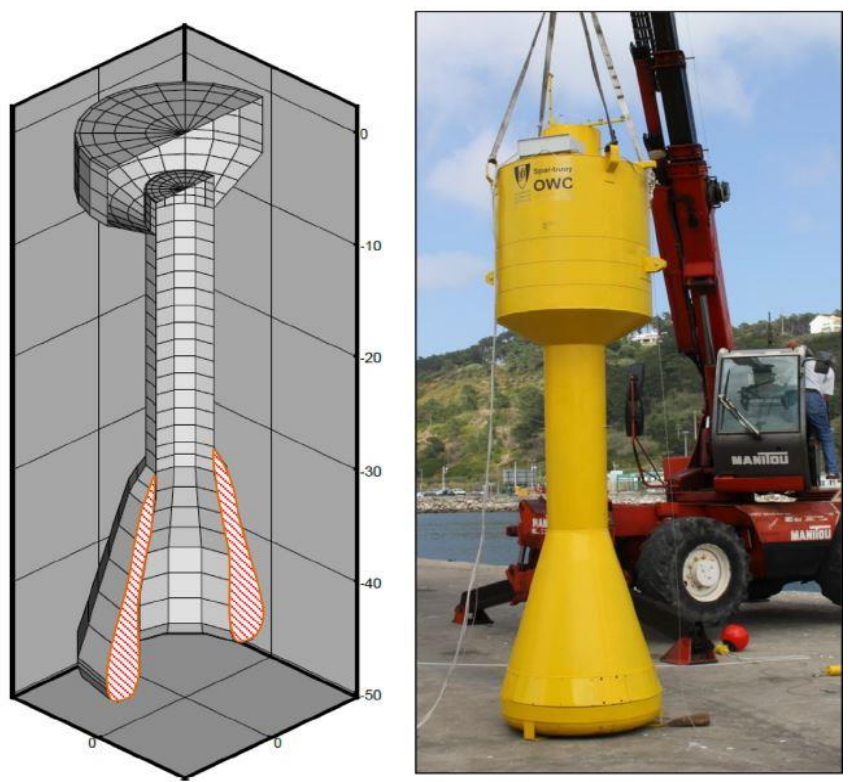

Figure 4 - Spar Buoy OWC [15]

\subsection{OWC Evolution}

The OWC has evolved from the original concept discussed with there now being many variations. For example, with more unconventional devices like the Floating OWC Drakoo Type B (Hann-Ocean) - a novel two chamber OWC design allegedly reaches an average CWR of 50\% [72]. Due to the key disadvantages of the OWC discussed regarding the bidirectional airflow and bandwidth or tune ability of a device, generally, innovations based on the OWC concept aim to resolve these disadvantages.

\subsubsection{Multi-resonant devices}

Variations of the OWC concept referred to as multi-resonant devices are self-tuning to operate efficiently in a wide range of frequencies based on the principle that different lengths of the water column effect the resonant period of the OWC [73].

An example of these single OWC multi-resonant devices is the Ocean Energy (OE) Buoy, which is based on the Backward Bent Duct Buoy concept (Fig. 5) [74], having an L-shaped chamber with the inlet facing in the direction of the propagating wave (away from the approaching crest). The concept was developed by Masuda in 1986 who found that by having an L-shaped duct rather than strictly vertical, increases the bandwidth of optimal operation and therefore improving performance in irregular waves $[15,74]$.

Multi-resonant capabilities have also been developed for the onshore application where there isn't necessarily the depths to extend chamber lengths. The answer was found with the U-shaped OWC - essentially extending the water column in order to create a tune ability and effectively 'force' resonance [75]. This concept found implemented with 
such devices like the Kvaener [76] and the breakwater synergy device REWEC3 (Resonant Wave Converter U-OWC) [77].

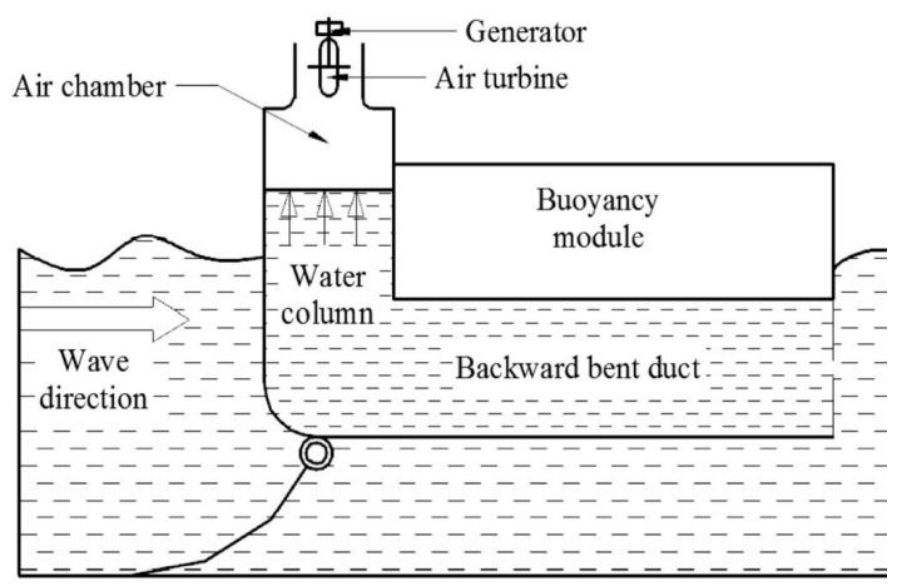

Figure 5 - Backward Bent Duct Buoy (BBDB) concept [74]

\subsubsection{Rectifying devices}

As discussed, a significant drawback to most singular OWC designs is the unidirectional airflow. While this is easier to overcome with M-OWCs, singular OWCs require further manipulation of the pneumatics in order to achieve unidirectional airflow. A spar buoy type device called the Tupperwave creates unidirectional airflow by having two additional chambers above the OWC, one for the inhalation and one for the exhalation situated downstream and upstream of an air turbine respectively. Therefore, the inhalation that would normally draw the air back through the turbine, actually acts upstream to maintain the original direction of both airflow and turbine rotation creating a closed system of airflow, as shown in Figure 6 [78] . Development of this device has been a work from University College Cork, Ireland, where 1:24 scale experiments were carried out. Experiments were ran for both regular and irregular waves with results compared to a conventional spar buoy OWC modelled in the same tests to give fair comparison. Performance results from the Tupperwave device have proven that the concept has potential to rival the original OWC. The main losses were apparently induced from the one-way valves, which imposed too much damping and did not open quickly enough [79].

A concept known as UniWave, being developed by Wave Swell Energy Ltd. from Australia also operates with a unidirectional flow turbine in a singular OWC device. However, airflow is only passing the turbine for half the wave period, which is during the inhalation of the air from the atmosphere. During the OWC heave, the pressurised air is exhausted directly to the atmosphere resulting in atmospheric pressure in the chamber at the maximum OWC heave point. Small scale (1:30) tests have been carried out from which the peak pneumatic efficiency in irregular waves was recorded at $83 \%$ [61]. 


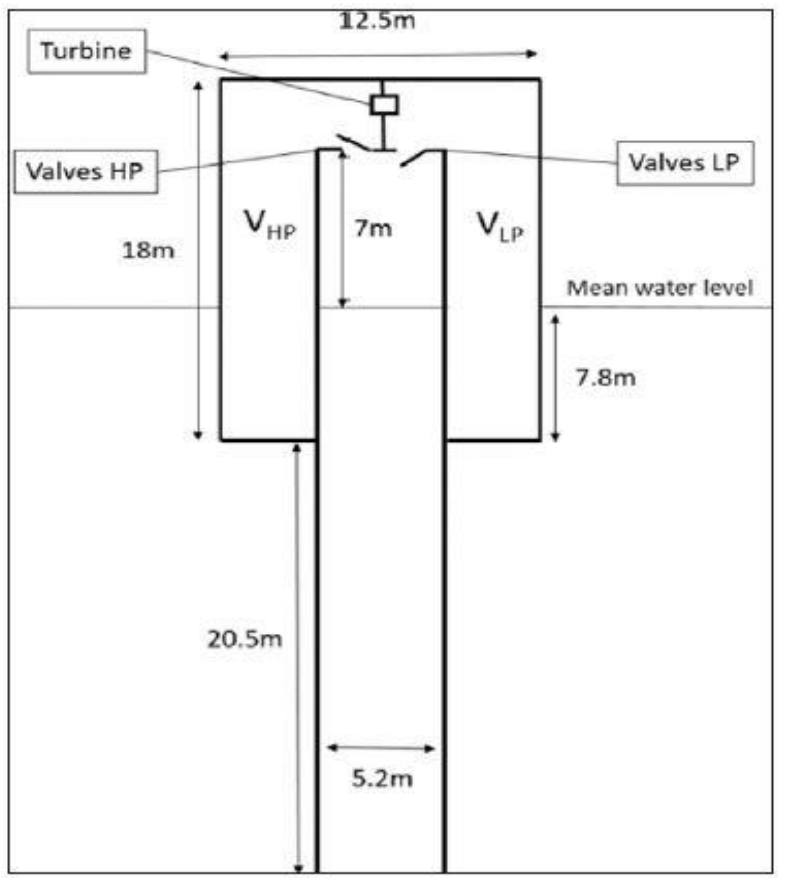

Figure 6 - Tupperwave concept sketch and full-scale dimensions [78] 


\section{Multi - Oscillating Water Columns}

\subsection{The Concept}

The multi-oscillating-water-column (M-OWC) concept, sometimes referred to as the multi-chamber oscillating water column (MC-OWC) [18], can be defined as an arrangement of OWC systems coupled together whether it be with regard to structure, airflow, PTOs or generators. The M-OWC concept was perhaps the original OWC concept of the Kaimei that comprised of multiple OWCs, which was essentially an OWC array. However, as discussed one of the disadvantages with OWC operation is the varying power output due to bidirectional airflow, the main issue more modern M-OWC concepts generally aim to resolve. Although self-rectifying turbine technology is improving, it is still an inefficient stage in the energy conversion, which gives the M-OWC a great advantage.

\subsubsection{M-OWC Categories}

It is important to clarify the three main applicable M-OWC sub-categories to be referred to as found in Ref. [13] with their respective illustrations in Figures 7a-c:

- OWC Array (Fig.7a): A device with multiple singular OWCs operating in isolation with individual turbines and generators but a housed in a common structure constituting one device

- Segmented M-OWC (Fig.7b): The turbines of multiple OWCs remain segregated but are mechanically coupled in order to have all operate the same one generator

- Modular M-OWC (Fig.7c): Multiple chambers providing airflow that is combined or accumulated and perhaps manipulated upstream of the turbine. Hence, the integration of the separate OWC systems occurs before the PTO stage to create a steady unidirectional airflow.

An M-OWC could be further sub-categorised, especially for segmented or modular M-OWCs. For example, modular M-OWCs vary with open or closed systems. Closed system devices create high and low pressure ducts downstream and upstream of the PTO respectively and therefore a large pressure differential. Hence, there is a controlled volume of working fluid in circulation. Open systems operate with high-pressure upstream and atmospheric pressure only downstream of the PTO. Since concepts significantly vary with no common trend developing, no further subcategories are defined at this stage. 


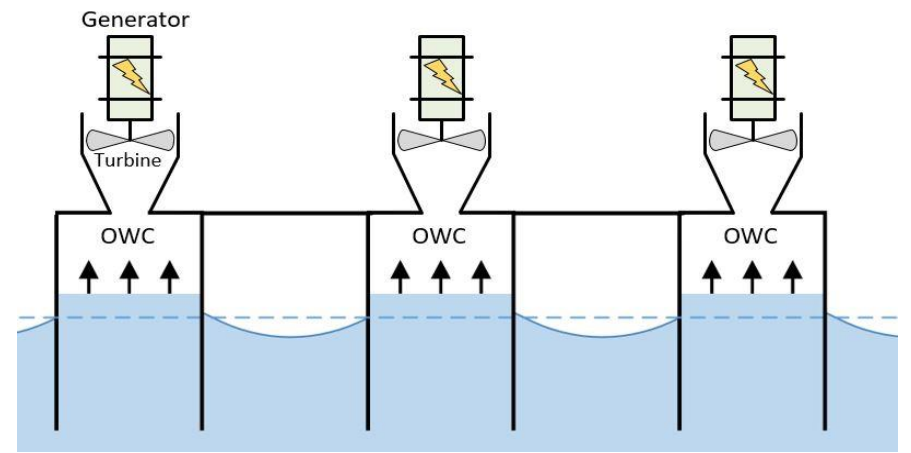

Figure 7a - OWC Array Concept

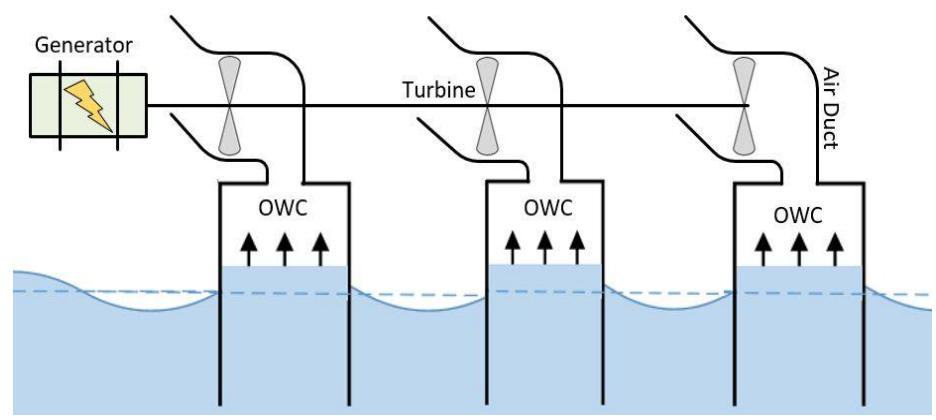

Figure 7b - Segmented M-OWC Concept

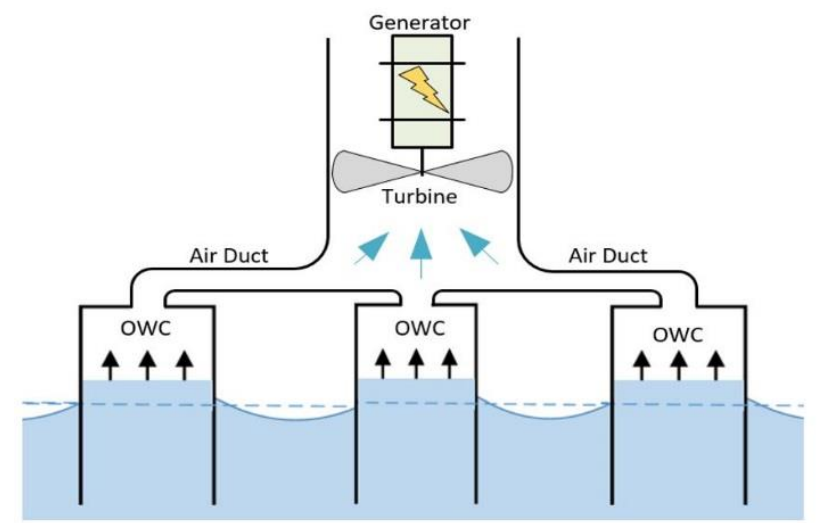

Figure 7c - Modular M-OWC Concept 


\subsection{M-OWC Devices}

Up until recent years, singular OWCs, arrays of singular OWCs within large structures (OWC arrays) and hybrid wind/wave energy structures have been the focal point of most OWC technology development. Many patents exist for different $\mathrm{M}-\mathrm{OWC}$ concepts and development has been steadily emerging with mainly offshore floating devices in attenuator formation. These more modern M-OWC concepts are modular systems, which are arranged with a smaller PTO to OWC ratio in order to obtain higher pressures and steady/unidirectional airflow rates.

\subsubsection{Floating Devices}

A two-chamber device named MORE, based on the M-OWC Seabreath concept (Fig. 8) was initially investigated in a MARINET project [80]. This floating device consists of several OWC chambers arranged in alignment with the wave propagation (perpendicular to the wave crest). Each OWC creates high and low pressures as the wave peaks and trough pass respectively. Unidirectional valves allow pressurised air during the compression process from each chamber to accumulate in a common high-pressure duct. Similarly, unidirectional valves allow flow from the lowpressure duct to fill the chamber as the water level recedes creating a negative pressure. As depicted in Figure 8, the high and low pressure ducts create a closed system with potentially more steady high-pressure flow differential across the turbine. An advantage of this closed system is that there will always be a constant supply of air even in less desirable conditions.

The early development work of the device has been well documented; initially experimental tests were carried out with a scaled device in a wave tank $36 \mathrm{~m}$ long [80]. During testing, a very low efficiency was recorded with respect to energy of the incident wave due to the two pressure ducts allegedly being too small. The concept boasts of the ability to harness irregular waves but in fact the pre-turbine performance reduced by $50 \%$ [80]. Further work done by Refs. [81, 82] with the concept includes numerical modelling providing experimentally validated performance predictions.
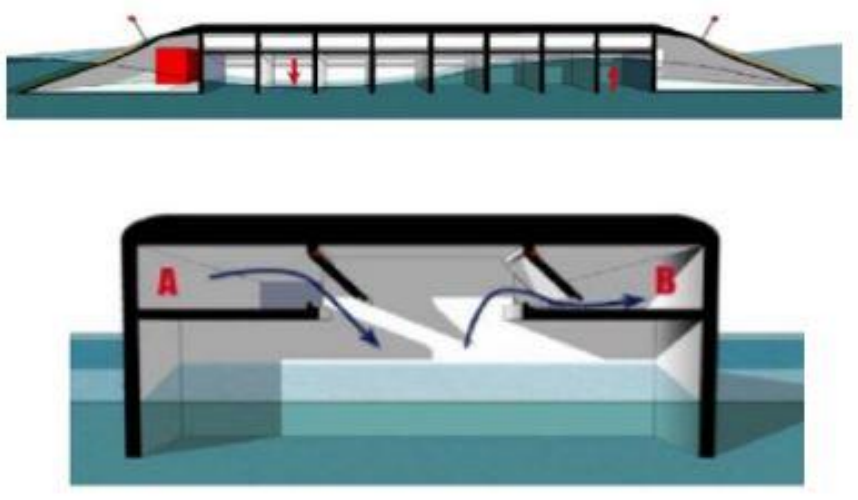

Figure 8 - Seabreath Concept [80] 
Similar to the Seabreath concept is the Australian invention patented in 2009 [83] developed by iVec named as the Floating Wave Power Plant (FWP) [84] and now known as the Wave Mill under Wave Power Engineering Ltd. [85]. The concept, as seen in Figure 9, comprises of multiple OWCs creating pressure differential with high and low pressure air ducts. The near shore system underwent sea trials in Brisbane, Australia (2009), and believed to have demonstrated very high efficiency ratings. Using a low efficiency turbine, the $30 \mathrm{~m}$ long prototype generated with a max efficiency of $81 \%$ and minimum of $41 \%$. Including a low efficiency generator, the wave to wire efficiency was calculated to be from $16 \%$ - 36\% for varying wave conditions. Costings of production at a commercial scale has been estimated but it appears no further developments have been published since 2014 [85].

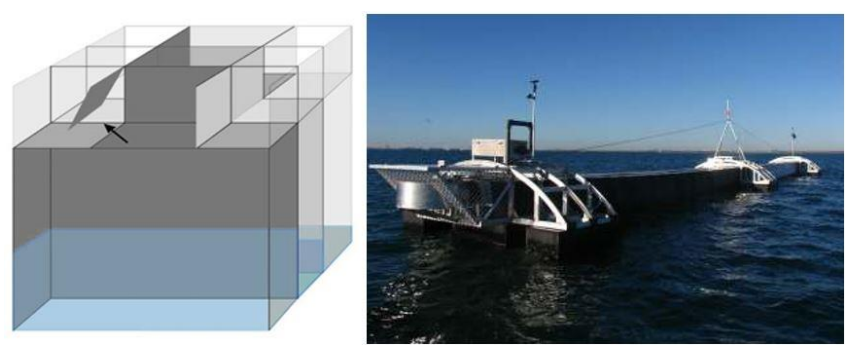

Figure 9 - Wave Mill Device [85]

Another MARINET project involved the M-OWC known as the KNSwing (Fig. 10), a ship-like structure with 20 OWCs either side of a central ballast (40 chambers total) [86-91].This concept is based on the Moody I-Beam Attenuator (1979) [87], with the I-beam cross sectional shape comprising of side entry chambers. The shape of the KNSwing is designed to induce minimal body response in waves, which has been proven in harsh scaled conditions and thus absorbs as much energy as possible through the OWCs $[86,88,90]$.

Initial experimental studies were carried out with a 1:50-100 model at the Hydraulics and Maritime Research Centre (HMRC) facility, University of Cork in 2013 [86, 89-91]. Aside from the various optimisation experimental findings and numerical analysis [87], the performance results were scaled to compare the peak CWR with other the Kaimei sea tests (1979 and 1982) and the Moody I-Beam experimental results (1979), all from which it falls short [86].

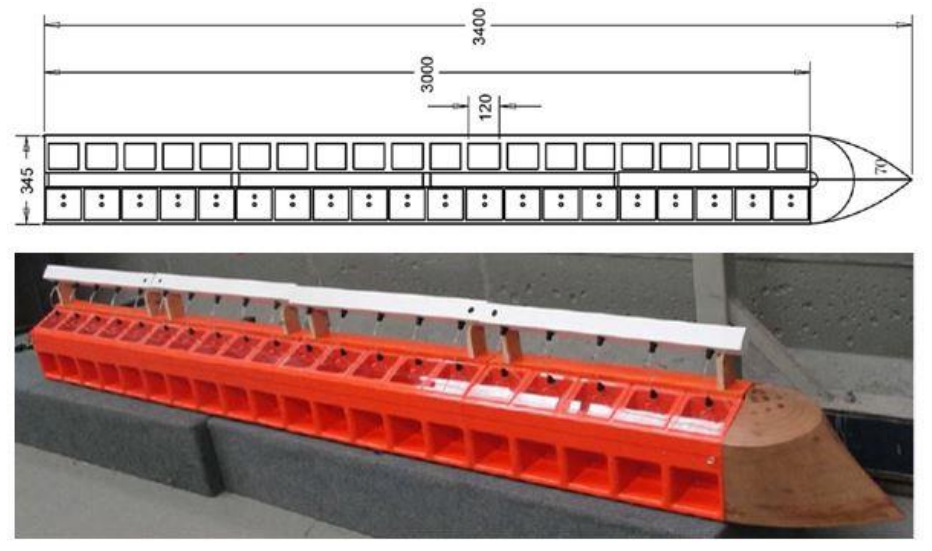

Figure 10 - KNSwing design sketch (top) and experimental model (bottom) [86, 87] 
The LEANCON device, patented in 2007 [92], is a floating V-shaped M-OWC that creates high and low pressures air ducts with an array of many small OWC tubes as depicted in Figure 11 [15]. The 'boomerang' or ' $\mathrm{V}$ ' shape, perhaps a terminator/attenuator hybrid, allows the WEC to capture a larger width of the wave. Theoretically, the large number of tubes create a balancing of forces as localised high and low pressures act within the tubes. The design is compact with air channels built into the structural design and a PTO system that comprises of turbine/s place between high and low pressure channels subject to unidirectional flow. The shape of the device and the array of tubes tilted with their openings toward the incident wave crest are intended to minimise wave impact forces and splash. Furthermore, the anchorage position, ideal when on the tip of the bow, helps the WEC to align with wave direction as the two arms cause a balancing effect [92].

In Ref. [93], experimental tests were carried out at HMRC and numerical modelling with a very similar but smaller model to the LEANCON at 1:50 scale with 32 tubes or OWCs [93]. Reports from a different 1:40 scale experiment conducted at the Aalborg University wave tank contain results for general hydrodynamic performance under various mooring configurations $[94,95]$. The bottom standing and floating configurations reached efficiencies reached $12.4 \%$ (3.56 GW/year) and 7.1-12\% (2.03-3.43 GW/year) respectively [95]. In December of 2015, a 1:10 scale LEANCON prototype with 104 tubes completed operational and structural tests at sea and was subsequently removed. Deployment is intended for the North Sea, off the Danish coast, after alleged 1:2 scale tests are carried out at the DanWEC facility [88].

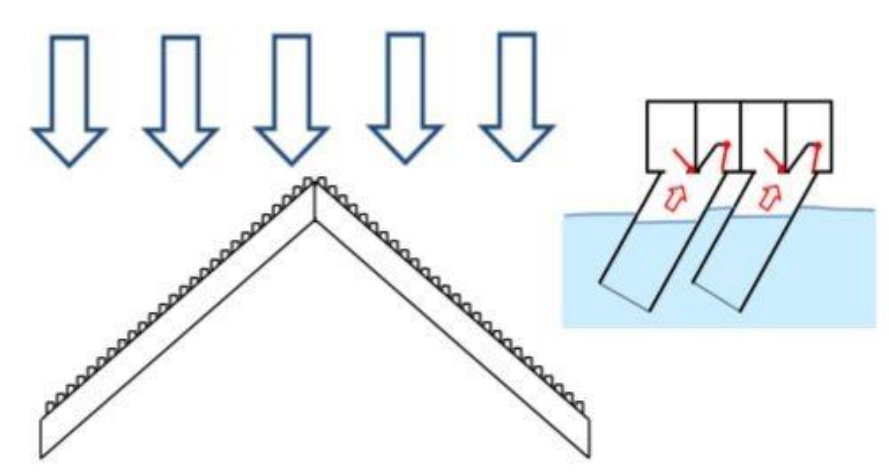

Figure 11 - LEANCON WEC orientation and operating principle [15]

A novel floating attenuator design patented by engineering entrepreneur Robin Kyffin [96], known as the Waves2Watts (W2W) M-OWC wave energy converter concept is now the subject of a research project at Lancaster University, UK. The Lancaster University Renewable Energy Group (LUREG) [17] is well known for WEC development with devices, such as the Lancaster Flexible Bag [48], WRASPA [97, 98], PS Frog [99], TALOS [100], EB Frond [101] and more. The W2W concept is unique and differs from the other M-OWCs reviewed in this paper in a number of respects. As seen in Figure 12, chambers are arranged in series along the length of the attenuator. Each chamber operates as an individual OWC, however, unidirectional air valves mean that chambers are pneumatically coupled to allow airflow in the same direction the propagation wave. At the first chamber, as a trough passes air is drawn from the atmosphere. The air is subsequently compressed as the peak arrives creating a higher pressure. This 
temporary pressure drop between the heaving chamber or fully elevated pressurised column and the subsequent chamber will assist in airflow and potentially create multi-stage compression type operation. The ideal occurrence of multi-stage air compression across an undefined number of chambers ends at a top tank (accumulator) before the PTO. The intention of the $\mathrm{W} 2 \mathrm{~W}$ is to create an open system where a high-pressure differential is achieved with respect to the atmosphere instead of having additional structures for separate low-pressure ducts. The combination of a highpressure differential and unidirectional flow should lead to higher first stage conversion efficiency.

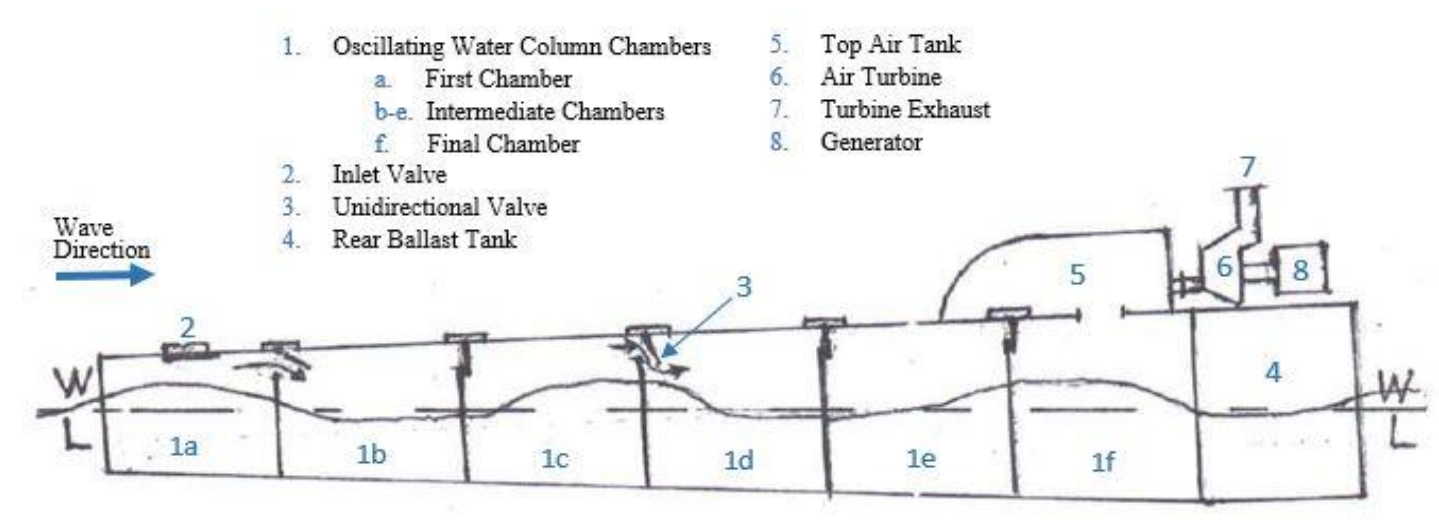

Figure 12 - Annotated original design sketch of the W2W concept [96]

Most OWCs are either onshore or semi-submerged floating structures unlike the Stellenbosh wave energy converter (SWEC) - a fully submerged shallow water, V-shaped breakwater integrated converter (Fig. 13) [102]. This M-OWC type, mounted on the sea floor, uses a closed loop unidirectional airflow system created by unidirectional valves and the high and low pressure manifolds as demonstrated in Figure 13 [102]. Chances of survivability are greater when submerged but components are exposed to increased corrosion rates.

In 1984, Ref. [103] carried out experiments on both 2D and 3D models from 1:100 to 1:50 scale [103]. Since then, the SWEC has been the subject of various studies coming out of Stellenbosch University, South Africa [102, 104, 105]. In more recent years, experimental studies with a 1:25 scale submerged single chamber model of the concept had been carried out, reaching a maximum conversion efficiency of $22 \%$. Although the concept is still being considered for specific applications and further development [106], the operational optimisation of the SWEC for these applications is still a working progress [107]. 


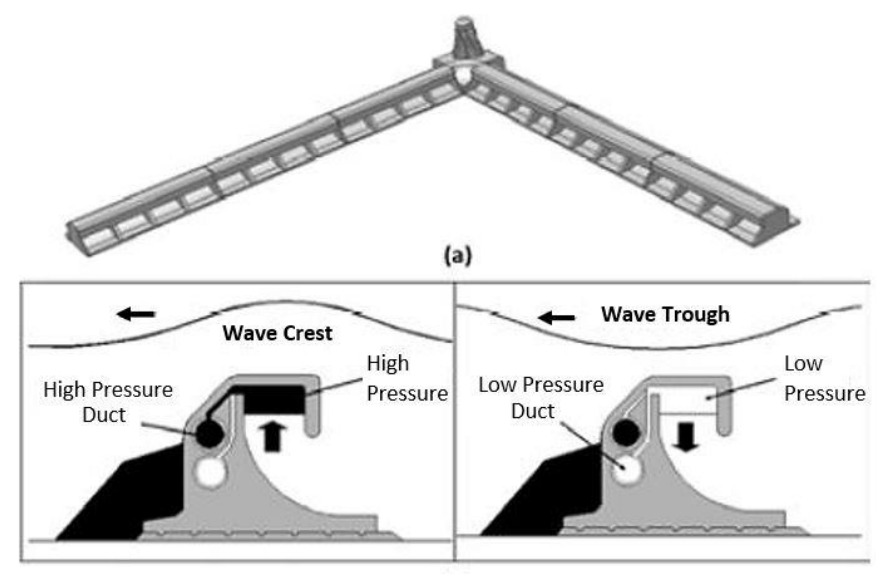

(b)

Figure 13 - Stellenbosch device arrangement (top) and operating principle (bottom) [104]

A fixed M-OWC concept and its variations have been the subject of research from Glasgow University initially in 2003 and more recently at University of Technology Sydney. This device is based on a concept with two to four chambers in either a segmented and modular arrangement. Initially models where tested with a Wells turbine before using just the savonius turbine in a segmented arrangement. Although this concept has been extensively investigated, there are still gaps in the research that are stunting its progression but should be a part of future work [18, 60, 108110].

Further M-OWC identified devices that have been found in literature but not discussed are the NEL Bottom Standing Terminator, Vickers Terminator and Vickers Attenuator, the NEL Floating Terminator and Attenuator, the OWC Belfast Point Absorber [48].

\subsubsection{Multi-resonant M-OWCs}

As with singular OWCs, resonance and the ability to tune to resonance is a desired trait. While solving the nature of the airflow with alternative M-OWC designs, if a greater bandwidth or a potential for more resonant peaks could be created, this would certainly set apart the M-OWC concept.

Based on a concept eventually patented in 2007 [111], the Orecon and its variants can be considered as a M-OWC as well as a Multi-Resonant Chamber (MRC). Figure 14 shows the MRC1000 and the Orecon Buoy, which Ref. [58] had performed various mooring based experiments at the Oceanide wave tank, France in 2009 [58, 112]. The design of the Orecon concept, having chambers of varying lengths, offers multiple resonant peaks and hence, great tune ability. As wavelengths vary in real irregular sea conditions, one OWC should at least approach resonant operation [111]. The MRC1000 device, reviewed in a 2004 report [112], is a floating offshore, slack-moored, 32m diameter WEC rated at 1 MW (full-scale) with a 3-stage PTO system, which includes an intermediary hydraulic stage. There are reports of wave tank experiments allegedly been carried with five different scaled models ranging from 1:250 and 1:20. Additionally, a 1:10 scale $5 \mathrm{~kW}$ prototype was tested at sea with plans for further seat trials in coming years [112]. However, in 2009 Orecon development seemed to have ceased due to financial support issues despite being so close to deployment of the 1 MW WEC [113]. 


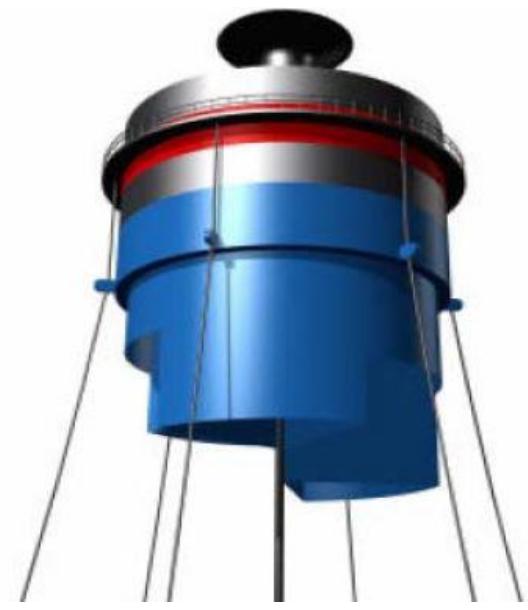

Figure 14 - MRC1000 ORECON Device [112]

\subsubsection{M-OWC Synergies}

With the current cost of wave energy and anticipation of a slow decline, innovative hybrid synergies are the subject of a lot of global research. Offshore synergies could play a large part in wave energy development with potential offshore platforms, large structures like breakwaters, energy plants or wind turbine platform integration.

Similar to the singular OWC synergy concepts mentioned, the Power Platform, by Global Renewable Solutions, is a wind turbine platform with six internal OWCs [114]. Synergies such as these are perhaps born from projects that envisage integration with wave energy at a latter stage. Hence, structures that have a primary purpose and later adapted, such as considered by Ref. [115] where the bare structure of a floating wind turbine platform is integrated with 3 OWCs. On a slightly larger scale, another example is the Rho-Cee, a Pneumatically Stabilised Platform (PSP) by Float Inc. [116]. The platform, known as an Impedance-Matched OWC (IM-OWC), contains a larger array of open bottom cylinders on the underside of the platform, which essentially take advantage of the air movement to provide stability. The platform can have a number of ancillary applications including wind energy hybrid, energy storage and generation.

As well as synergies across other ocean energy fields, integration of multiple WEC operational concepts exist. An example in the work of Ref. [117], where a combination of an OWC and overtopping device known as an Oscillating and Overtopping Water Column (O-OWC) has been experimentally modelled. 


\subsection{Performance Baselines}

Device performance figures as collated by Ref. [38], reveal that the present M-OWCs performance values do not show significant improvements from the singular OWCs such as the (OE) Buoy. When compared to other types of WECs, as in Table 2 [38], OWCs are most competitive with the fixed oscillating wave surge converters (OWSCs). Currently, with the few very mixed performance predictions of small scale M-OWCs it is hard to determine whether they could be competitive at this stage. Thus far, modular type M-OWC performances and predictions have not been good enough to compete with various singular OWCs. The CWR data summarised by Ref. [38] and in Table 2 essentially reveals the benchmarks and shows that for OWCs, and as with other WEC categories, currently no device performance significantly outweighs the rest.

Table 2 - Mean and standard deviation of CWR across WEC categories [38]

\begin{tabular}{ccccccc}
\hline & OWCs & Overtopping & $\begin{array}{c}\text { Heaving } \\
\text { Devices }\end{array}$ & $\begin{array}{c}\text { Fixed } \\
\text { OWSCs }\end{array}$ & $\begin{array}{c}\text { Floating } \\
\text { OWSCs }\end{array}$ \\
\hline $\begin{array}{c}\text { Capture } \\
\text { Width Ratio } \\
(\%)\end{array}$ & Mean & 29 & 17 & 16 & 37 & 12 \\
& STD & 13 & 8 & 10 & 20 & 5 \\
$\begin{array}{c}\text { Characteristic } \\
\text { dimension (m) }\end{array}$ & Mean & 20 & 124 & 12 & 18 & 33 \\
\hline
\end{tabular}

\section{Concluding Remarks}

The development of wave energy technologies is progressing around the world while it is still lagging behind the developmental stages of other renewable energies with no visible convergence of technologies to date. The excellent global resource potential provide a very good incentive for further development of competitive wave energy technologies.

This paper reviews the concept of the OWC, its evolution and development. The M-OWC has been introduced with background on operational theory, terminologies and details of the known devices in development over recent years as summarised in Table 3.

The majority of devices that exist are floating or fixed attenuator types with closed pneumatic systems comprising of low and high-pressure ducts. The greatest advantage of these modular M-OWC systems over the singular OWC being the steady unidirectional airflow denying need for less efficient but most commonly installed self-rectifying turbines. This is a logical step in improving overall efficiency in the first stage of energy conversion alone. Furthermore, it has been suggested that due to the versatility and potential of the M-OWC, concepts may include opportunity to increase 
bandwidth of optimal operation with multiple resonant frequencies. Based on the evolution of the OWC and in light of its disadvantages, the M-OWC concepts offers significant theoretical improvements. Such concepts have been subjects of investigations but at present are still far from commercialisation.

Although the M-OWC has great potential, performance reports from scaled experiments and trials suggest there is still a lot room for development. Competitiveness with a substantially better conversion efficiency is key in order to justify larger structures such as M-OWCs over singular OWCs. Novel devices such as the W2W presented and the development intended is a step in the direction toward gaining further understanding and contributing to the wave energy community in the challenge of extracting energy from ocean waves. Both OWCs and M-OWCs remain to be a versatile and diverse WEC concept allowing integration in a variety of applications as discussed. For example, large structures like the W2W could be moored offshore and be integrated with other technologies such as wind and solar power, offshore platforms and breakwaters. The ocean energy industry will ultimately steer toward these synergies to create more cost effective deployment and power production. It is clear that the M-OWC has not been developed enough, but there remains to be a gap in research and a remnant of potential outcomes to be investigated, which should be further explored. 
Table 3 - Summary of M-OWCs reviewed

\begin{tabular}{|c|c|c|c|c|c|c|}
\hline $\begin{array}{l}\text { Company/ } \\
\text { Institution }\end{array}$ & Device Name & $\begin{array}{l}\text { Sub- } \\
\text { categories }\end{array}$ & $\begin{array}{l}\text { Number of } \\
\text { OWCs }\end{array}$ & $\begin{array}{l}\text { Max. Scale } \\
\text { Tested }\end{array}$ & $\begin{array}{c}\text { Latest } \\
\text { Publication }\end{array}$ & Refs. \\
\hline MARINET & MORE/Seabreath & $\begin{array}{l}\text { Modular } \\
\text { M-OWC }\end{array}$ & $\geq 2$ & $\begin{array}{l}36 \mathrm{~m} \\
\text { Length }\end{array}$ & 2014 & $\begin{array}{l}{[80-} \\
82]\end{array}$ \\
\hline $\begin{array}{l}\text { Wave Power Plant } \\
\text { (FWP) / Wave Power } \\
\text { Engineering Ltd. }\end{array}$ & Wave Mill / iVec & $\begin{array}{l}\text { Modular } \\
\text { M-OWC }\end{array}$ & $>2$ & $\begin{array}{l}30 \mathrm{~m} \\
\text { Length }\end{array}$ & - & $\begin{array}{l}{[83-} \\
85]\end{array}$ \\
\hline MARINET & KNSwing & $\begin{array}{l}\text { Modular } \\
\text { M-OWC }\end{array}$ & 40 & $1: 50$ & 2015 & $\begin{array}{l}{[86,} \\
88- \\
91]\end{array}$ \\
\hline $\begin{array}{c}\text { Aalborg University and } \\
\text { HMRC }\end{array}$ & LEANCON & $\begin{array}{l}\text { Modular } \\
\text { M-OWC }\end{array}$ & 104 & $1: 10$ & 2013 & $\begin{array}{l}{[88,} \\
92- \\
95]\end{array}$ \\
\hline $\begin{array}{l}\text { Stellenbosch } \\
\text { University }\end{array}$ & Stellenbosch & $\begin{array}{l}\text { Modular } \\
\text { M-OWC }\end{array}$ & - & $1: 25$ & 2017 & $\begin{array}{l}{[102-} \\
107]\end{array}$ \\
\hline $\begin{array}{l}\text { Lancaster University } \\
\text { and Waves2Watts Ltd. }\end{array}$ & Waves2Watts & $\begin{array}{l}\text { Modular } \\
\text { M-OWC }\end{array}$ & $>2$ & $1: 50$ & 2018 & $\begin{array}{l}{[17,} \\
96]\end{array}$ \\
\hline $\begin{array}{c}\text { University of Glasgow, } \\
\text { Taiwan National } \\
\text { Science } \\
\text { Council and } \\
\text { University of } \\
\text { Technology } \\
\text { Sydney } \\
\end{array}$ & - & $\begin{array}{l}\text { Segmented / } \\
\text { Modular } \\
\text { M-OWC }\end{array}$ & $\geq 2$ & - & 2017 & $\begin{array}{l}{[18} \\
60 \\
108- \\
110]\end{array}$ \\
\hline Orecon & MRC1000 & $\begin{array}{c}\text { MRC, } \\
\text { Modular M- } \\
\text { OWC }\end{array}$ & $>2$ & $\begin{array}{l}32 \mathrm{~m} \\
\text { Diameter }\end{array}$ & 2009 & $\begin{array}{l}{[58} \\
111- \\
113]\end{array}$ \\
\hline $\begin{array}{l}\text { Global Renewable } \\
\text { Solutions }\end{array}$ & Power Platform & $\begin{array}{l}\text { M-OWC } \\
\text { Synergy }\end{array}$ & 6 & - & - & [114] \\
\hline Float Inc. & $\begin{array}{c}\text { Rho-Cee, } \\
\text { Pneumatically } \\
\text { Stabilised Platform }\end{array}$ & IM-OWC & - & - & - & [116] \\
\hline
\end{tabular}

\section{Acknowledgements}

This work is funded by the European Union through its European Regional Development Fund (ERDF) and the Centre of Global Eco-Innovation and industrial partners Waves2Watts Ltd. 


\section{References}

[1] REN21 Renewable Energy Policy Network for 21st Century, Renewables 2018 - Gloabl Status Report. Paris 2018.

[2] Lopez.I, Andreu, J, Salvador, C, Martínez de Alegría, I, Kortabarria, I. Review of Wave Energy Technologies. Renewable and Sustainable Energy Reviews and The Necessary Power-equipment. 2013;27:413-34.

[3] International Energy Outlook 20172017.

[4] The Outlook for Energy: A View to 2040. Irving, Texas 2016.

[5] Drew, B, Plummer, A R, Sahinkaya, M. A Review of Wave Energy Converter Technology. Proceedings of the Institution of Mechanical Engineers Part A Journal of Power and Energy. December, 2009.

[6] Cruz, J. OceanWave Energy: Current Status and Future Prepectives. Berlin , Heidelberg, Germany: Springer-Verlag 2008.

[7] Khan.N, Kalair, A, Abas, N, Haider, A. Review of Ocean Tidal, Wave and Thermal Energy Technologies. Renewable and Sustainable Energy Reviews. 2017;72:590-604.

[8] Melikoglu, M. Current status and future of ocean energy sources: A global review. Ocean Engineering. 2018;148:563-

[9] Magagna, D, Uihlein, A. Ocean energy development in Europe: Current status and future perspectives. International Journal of Marine Energy. 2015;11:81-104.

[10] Magagna, D, Riccardo, M, Uihlein, A. JRC Ocean Energy Status Report 2016.

[11] Falcao, A F O. Wave energy utilization: A review of the technologies. Renewable and Sustainable Energy Reviews. 2010;14:899-918.

[12] Heath, T V. A review of oscillating water columns. Phil Trans R Soc A. 2012;235-245:370.

[13] Delmonte, N, Barater, D, Giuliani, F, Cova, P, Buticchi, G. Oscillating Water Column Power Conversion: a Technology Review. IEEE Transactions on Industrial Applications. 2014:1852-9.

[14] Titah-Benbouzid, H, Benbouzid, M. An Up-to-Date Technologies Review and Evaluation of Wave Energy Converters. International Review of Electrical Engineerings - IREE. 2015;10:52-61.

[15] Falcao, A F O, Henriques, J C C. Oscillating-water-column wave energy converters and air turbines: A Review. Renewable Energy. 2016;85:1391-424.

[16] Lindroth, S, Leijon, M. Offshore wave power measurements - A review. Renewable and Sustainable Energy Reviews. 2011;15:4274-85.

[17] Doyle, S, Aggidis, G A. Investigation into Multi-Oscillating Water Column Wave Energy and a Novel Concept. Proceedings of the 3rd International Conference on Renewable Energies Offshore (RENEW-2018 ). Lisbon, Portugal2018.

[18] Shalby, M, Dorrel, D G, Walker, P. Multi-chamber oscillating water column wave energy converters and air turbines: A review. International Journal of Energy Research. 2018:1-16.

[19] Reguero, B G, Losada, I J, Mendez, F J. A global wave power resource and its seasonal, interannual and long-term variability. Applied Energy. 2015;148:366-80.

[20] Bahaj, A S. Generating electricity from the oceans. Renewable and Sustainable Energy Reviews. 2011;15:3399-416.

[21] Arinaga, R A, Cheung, K F. Atlas of global wave energy from 10 years of reanalysis and hindcast data. Renewable Energy. 2012;39:49-64.

[22] Barstow, S, Mork, G, Lonseth, L, Mathisen, J P. WorldWaves wave energy resource assessments from the deep ocean to the coast. Proceedings of the 8th European Wave and Tidal. Uppsala, Sweden2009.

[23] Mustapa, M A, Yaakob, O B, Ahmed, Y M, Rheem, C, Koh, K K, Adnan, A A. Wave energy device and breakwater integration: A review. Renewable and Sustainable Energy Reviews. 2017;77:43-58.

[24] Portilla, J, Sosa, J, Cavaleri, L. Wave Energy resources: Wave climate and exploitation. Renewable Energy. 2013;57:594605.

[25] Folley, M, Whittaker, T J T. Analysis of the nearshore wave energy resource. Renewable Energy. 2009;34:1709-15.

[26] Beels, C, Henriques, J C C, De Rouck, J, Pontes, M T, De Backer, G, Verhaeghe, H. Wave energy resource in the North Sea. Proceedings of the 7th European Wave and Tidal Energy Conference. Porto, Portugal2007.

[27] Fairley, I, Williams, H E, Horrilo-Caraballo, J, Thompson, D, Masters, I, Reeve, D E, Karunarathna, H, Faraggiana, E. An analysis of the wave climate in South Wales, UK. Proceedings of the 12th EWTEC Conference. Cork, Ireland2017.

[28] Illesinghe, S J, Manasseh, R, Dargaville, R, Ooi, A. Idealized design parameters of Wave Energy Converters in a range of ocean wave climates. International Journal of Marine Energy. 2017;19:55-69. 
[29] Thomas, A, Mason-Jones, R, Turner, D, Davies, P, O'Doherty, T, O'Doherty, D, Mason-Jones, A. Tidal and marine energy in the UK - Identifying the future challenges for supply chain development. Proceedings of the 11th International Conference on Manufacturing Research (ICMR2013). Cranfield University, UK2013.

[30] The Carbon Trust - UK wave energy resource 2012.

[31] Uk Wave and Tidal Key Resource Areas Project - Summary Report 2012.

[32] Wave and Tidal Energy Market Deployment Strategy for Europe 2014.

[33] Idustry Vision Paper. Brussels, Belgium 2013.

[34] Falcao, AF O. The Development of Wave Energy Utilization. Global Status and Critical Developments on Ocean Energy. 2008:15-22.

[35] Zhang, H, Aggidis, G A. Nature rules hidden in the biomimetic wave energy converters. Renewable and Sustainable Energy Reviews. 2018;97:28-37.

[36] Cui, Y. Simulation of Wave Energy Harvesting by Piezoelectric Seaweed. IWMSE2017 - IOP Conf Series: Materials Science and Engineering 2500120222017.

[37] Marine Energy - Wave Devices. Marine Energy - Wave Devices, http://www.emec.org.uk/marine-energy/wavedevices//; [Accessed: 10 January 2018].

[38] Babarit, A. A database of capture width ratio of wave energy converters. Renewable Energy. 2015;80:610-28.

[39] Joubert, J R, van Niekerk, J L, Reinecke, J, Meyer, I. Wave Energy Converters (WECs) 2013.

[40] The Executive Committee of Ocean Energy Systems, Annual Report - Ocean Energy Systems 2016.

[41] Ingram, D, Smith, G, Bittencourt-Ferreira, C, Smith, H. Protocols for the Equitable Assessment of Marine Energy Converters. Edinburgh 2011.

[42] Ocean Energy: Development and Evaluation Protocol 2003.

[43] Holmes, B, Nielsen, K. Report T02-2.1 - Guidelines for the Development \& Testing of Wave Energy Systems 2010.

[44] Offshore Renewable Energy. Proceedings of the 20th International Ship and Offshore Structures Congress (ISSC 2018)

2018 .

[45] Commercial Readiness Index Assessment. Utrecht 2017.

[46] de Andreas, A, MacGillivray, A, Roberts, O, Guanche, R, Jeffrey, H. Beyond LCOE: A study of ocean energy technology development and deployment attractiveness. Sustainable Energy Technologies and Assessments. 2017;19:1-16.

[47] Lehmann, M, Karimpour, F, Goudey, C A, Jacobson, P T, Alam, M R. Ocean wave energy in the United States: Current status and Future Perspectives. Renewable and Sustainable Energy Reviews. 2017;74:1300-13.

[48] Consulting Engineers Rendel Palmer \&Tritton, Consultants 1981 assessment. London, UK 1982.

[49] R Kempener, F N. IRENA - International Renewable Energy Agency, Wave Energy Technology Brief 42014.

[50] Astariz, S, Iglesias, G. The economics of wave energy: A review. Renewable and Sustainable Energy Reviews. 2015;45:397- 408 .

[51] O'Hagan, A M, Huertas, C, O'Callaghan, J, Greaves, D. Wave energy in Europe: Views on experiences and progress to date. International Journal of Marine Energy. 2016;14:180-97.

[52] Background Papers on Seafloor Engineering, Volume 2: Assembly of Engineering National Research Council; 1975.

[53] Masuda, Y. Wave-Activated Power Generator Publisher; 1989, US4858434.

[54] Washio, Y, Osawa, H, Nagata, Y, Fujii, F, Furuyama, H, Fujita, T. The Offshore Floating Type Wave Power Device "Mighty Whale": Open Sea Tests. Proceedings of the Tenth (2000) International Offshore and Polar Engineering Conference. Seattle, USA2000.

[55] Washio, Y, Osawa, H, Ogata, T. The Open Sea Tests of The Offshore Floating Type Wave Power Device "Mighty Whale" - Characteristics of Wave Energy Absorption and Power Generation. An Ocean Odyssey Conference Proceedings (IEEE Cat No01CH37295). Honolulu: Japan Marine Science and Technology Center; 2001.

[56] Brooke, J. Wave Energy Conversion. Oxford, UK: Elsevier Science Ltd; 2003.

[57] Badhurshah, R, Samad, A, Karthikeyan, T. Oscillating Water Column Wave Energy System - A Prospective. First International Conference on Automation, Control, Energy and Systems. Hoogly, West Bengal, India2014.

[58] Lye, J L, Brown, D T, Johnson, F. An Investigation into the Non-linear Effects Resulting from Air Cushions in the Orecon Oscillating Water Column (OWC) Device. Proceedings of the ASME 2009 28th International Conference on Ocean, Offshore and Arctic Engineering. Honolulu, Hawaii, USA2009.

[59] Falcao, A F O, Henriques, J C C, Gato, L M C. Self-rectifying air turbines for wave energy conversion: A comparative analysis. Renewable and Sustainable Energy Reviews. 2018;91:1231-41.

[60] Dorrell, D G, Hsieh, M, Lin, C. A Multichamber Oscillating Water Column Using Cascaded Savonius Turbines. IEEE Transactions on Industry Applications. 2010;46:2372-80.

[61] Fleming, A, MacFarlane, G, Hunter, S, Denniss, T. Power Performance Prediciton for a Vented Oscillating Water Column Wave Energy Converter with a Unidirectional Air Turbine Power Take-Off. Proceedings of the 12th European Wave and Tidal Energy Conference. Cork, Ireland2017. 
[62] El Marjani, A, Castro Ruiz, F, Rodriguez, M A, Parra Santos, M T. Numerical modelling in wave energy conversion systems. Energy. 2008;33:1246- 53.

[63] Falcao, A F O, Gato, L M C, Sarmento, A J N A, Brtio-Melo, A. The Pico OWC wave power plant: Its life from conception to closure 1986-2018. Proceedings of the 3rd International Conference on Renewable Energies Offshore (RENEW-2018). Lisbon, Portugal2018.

[64] Whittaker, T J T, Beattie, W, Folley, M, Boake, C, Wright, A, Osterried, M, Heath, T. The LIMPET Wave Power Project - The first years of operation. Renewable Energy. 2004.

[65] The Queen's University of Belfast, Islay LIMPET Wave Power Plant: Commission TE; 2002.

[66] Baudry, V, Babarit, A, Clement, A. An overview of analytical, numerical and experimental methods for modelling oscillating water columns. Proceedings of the 10th European Wave and Tidal Energy Conference. Aalbord, Denmark2013.

[67] Takahashi, S, Nakada, H, Ohneda, H, Shikamori, M. Wave Power Covnersion by a Prototype Wave Power Extracting Caisson in Sakata Port. Costal Engineering 1992. p. 3440-53.

[68] Torre-Enciso, Y, Ortubia, I, Lopez de Aguileta, L I, Marques, J. Mutriku Wave Power Plant: from the thinking out to the reality. Proceedings of the 8th European Wave and Tidal Energy Conference. Uppsala, Sweden2009.

[69] Sutton, M. ABC News. ABC News, http://www.abc.net.au/news/2017-05-17/oceanlinx-generator-stranded-as-courtproceedings-continue/8529602/; 2017 [Accessed: 17 May 2018].

[70] Oceanlinx sinks into liquidation. Oceanlinx sinks into liquidation, http://tidalenergytoday.com/2014/12/23/oceanlinxgoes-into-liquidation//; 2014 [Accessed: 10 September 2018].

[71] Medina-Lopez, E, Allsop, W, Dimakopoulos, A, Bruce, T. Conjectures on the Failure of the OWC Breakwater at Mutriku. Conference: Coastal Structures. Boston, USA2015.

[72] DRAKOO Wave Energy Converter. DRAKOO Wave Energy Converter, http://www.hannocean.com/index.php/products/drakoo.html/; [Accessed: 10 September 2018].

[73] Sheng, W, Lewis, T, Alcorn, R. On wave energy extraction of oscillating water column device. 4th International Conference on Ocean Energy. Dublin, Ireland2012.

[74] Wu, B, Li, M, Wu, R, Chen, T, Zhang, Y, Ye, Y. BBDB wave energy conversion technology and perspective in China. Ocean Engineering. 2018;169:281-91.

[75] Boccotti, P. On a new wave energy absorber. Ocean Engineering. 2003;30:1191-200.

[76] Hubble, J. Wave power - Norway's latest export. Electronics and Power. 1986:533-4.

[77] REWEC3 - Innovative breakwaters to produce energy from ocean waves. REWEC3 - Innovative breakwaters to produce energy from ocean waves, http://www.wavenergy.it//; [Accessed: 10 September 2018].

[78] Benreguig, P, Murphy, J, Vicente, M, Crowley, S. Wave-to-wire model of the Tupperwave device and performance comparison with conventional OWC. Proceedings of the 3rd International Conference on Renewable Energies Offshore (RENEW-2018 ). Lisbon, Portugal2018.

[79] Benreguig, P, Murphy, J, Sheng, W. Model Scale Testing of the Tupperwave Device with Comparison to a Conventional OWC. Proceedings of the ASME 2018 International Design Engineering Technical Conferences \& Computers and Information in Engineering Conference. Madrid, Spain2018.

[80] Delmonte, N, Ruol, P, Martinelli, L, Giuliani, F, Cova, P. Multi-chamber oscillating water column device for harvesting Ocean Renewable Energy 2014.

[81] Martinelli, L, Ruol, P, Fassina, E, Giuliani, F, Delmonte, N. A Wave-2-Wire Experimental Investigation of the New "Seabreath" Wave Energy Converter: The Hydraulic Response. Coastal Engineering. 2014.

[82] Martinelli, L, Ruol, P, Cortellazzo, G. On Mooring Design of Wave Energy Converters: The Seabreath Application. Coastal Engineering. 2012.

[83] Voropaev, I. Nautilis Patent Publisher; 2009, US20090102199A1.

[84] New Technologies Open New Horizons. New Technologies Open New Horizons, http://www.ivec.com.au/; 2011 [Accessed: 10 September 2018].

[85] Wave Mill. Wave Mill, http://wavepowerengineering.com/; [Accessed: 10 September 2018].

[86] Nielsen.K. MARINET experiment KNSWING testing an I-Beam OWC attenuator. International Journal of Marine Energy. 2015;12:21-34.

[87] Bingham, H B, Ducasse, D, Nielsen, K, Read, R. Hydrodynamic analysis of oscillating water column wave energy devices. Journal of Ocean Engineering. 2015;1:405-19.

[88] Thomsen, J B. Hydrodynamic Models of Partner WECs 2018.

[89] Nielsen K, B O, Jacobsen F P MARINET - Marine Renewables Infrastructure Network, Attenuator development phase Ib. 2015.

[90] Nielsen K, B O. MARINET - Marine Renewables Infrastructure Network, Attenuator development phase I c 2015. 
[91] Nielsen K, J F P, Simonson M, Scheijgrond P. MARINET - Marine Renewables Infrastructure Network, Attenuator development phase I 2013.

[92] Rasmussen, K D. Wave Energy Converter Comprising Pressure and Suction Pipes Publisher; 2007, WO 2007057013 A1.

[93] Kelly, T, Dooley, T, Campbell, J, Ringwood, J V. Comparison of the Experimental and Numerical Results of Modelling a 32-OscillatingWater Column (OWC), V-Shaped Floating Wave Energy Converter. Energies. 2013;6:4045-77.

[94] Frigaard, P B, Kofoed, J P, Beserra, E R. Wave induced loads on the LEANCON wave energy converter 2008.

[95] Kofoed, J P, Frigaard, P B. Hydraulic evaluation of the Leancon wave energy converter 2008.

[96] Kyffin, R. A Floating Multistage Air Compressor With Turbine Publisher; 2012, US 4466244 A.

[97] Aggidis, G A, Rahmati, M T, Chaplin, R V, McCabe, A P, Bhinder, M A, Mingham, C G, Causon, D M. Optimum Power Capture of a New Wave Energy Converter in Irregular Waves. Proceedings of the ASME 28th International Conference on Ocean, Offshore and Arctic Engineering. Honolulu, Hawaii, USA2009.

[98] Bhinder, M A, Mingham, C G, Causon, D M, Rahmati, M T, Aggidis, G A, Chaplin, R V. A joint numerical and experimental study of a surging point absorbing wave energy converter (WRASPA). Proceedings of the ASME 28th International Conference on Ocean, Offshore and Arctic Engineering. Honolulu, Hawaii, USA2009.

[99] McCabe, A P, Bradshaw, A, Meadowcroft, J A C, Aggidis, G A. Developments in the design of the PS Frog Mk 5 wave energy converter. Renewable Energy. 2006;31:141-51.

[100] Aggidis, G A, Taylor, C J. Overview of wave energy converter devices and the development of a new multi-axis laboratory prototype. IFAC PapersOnLine. 2017;50:15651-6.

[101] EB Frond Wave Energy Converter - Phase 22005.

[102] Joubert, J R. Design and Development of a Novel Wave Energy Converter (PhD Thesis) 2013.

[103] Retief, G d F, Muller, F, Prestedge, G, Geustyn, L, Swart, D. Detailed Design of a Wave Energy Conversion Plant. Costal Engineering. 1984:2546-62.

[104] Ackerman, P H. Air Turbine Design Study for a Wave Energy Conversion System (Thesis) 2009.

[105] Fairhurst, J. Modelling and Design of an Oscillating Wave Energy Converter (Thesis) 2015.

[106] Fairhurst, J, Van Niekerk, J L. Development and application of a wave energy conversion simulation model. Proceedings of the 12th European Wave and Tidal Energy Conference. Cork, Ireland2017.

[107] Fairhurst, J, Van Niekerk, J L. Modelling, simulation and testing of a submerged oscillating water column. International Journal of Marine Energy. 2016;16:181-95.

[108] Shalby, M, Walker, P, Dorrel, D G. Modelling of the multi-chamber oscillating water column in regular waves at model scale. 4th International Conference on Energy and Environment Research, ICEER 2017. Porto, Portgual2017.

[109] Shalby, M, Walker, P, Dorrel, D G. The Investigation of a Segment Multi-Chamber Osciallting Water Column in Physical Scale Model. 5th International Conference on Renewable Energy Research and Applications. Birmingham, UK2016.

[110] Shalby, M, Walker, P, Dorrel, D G. The Characteristics of the Small Segment Multi-Chamber Oscillating Water Column. 3rd AWTEC (Asian Wave and Tidal Energy Conference Series). Singapore2016.

[111] Johnson, F J E. Wave Energy Device Publisher; 2007, US20070180823 A1.

[112] Previsic, M, Bedard, R, Hangerman, G. E2I EPRI Assessment - Offshore Wave Energy Conversion 2004.

[113] Wave energy Developer Orecon hits stormy waters. Wave energy Developer Orecon hits stormy waters, http://www.renewableenergyfocus.com/; 2009 [Accessed: 01 May 2018].

[114] GRS' Concept. GRS' Concept, http://www.globalrenewablesolutions.org/pages/mpt-s-concept.html/; [Accessed: 01 October 2018].

[115] Mazarakos, T P, Mavrakos, S A. Second order wave drift damping of a TLP floating structure concept for combined wind and wave energy. Proceedings of the 3rd International Conference on Renewable Energies Offshore (RENEW2018 ). Lisbon, Portugal2018.

[116] An innovative Wave Energy Converter (WEC), the "Rho-Cee". An innovative Wave Energy Converter (WEC), the "Rho-Cee", http://www.floatinc.com/; [Accessed: 01 October 2018].

[117] Cappietti, L, Simonetti, I, Penchev, V, Penchev, P. Laboratory tests on an original wave energy converter combining oscillating water column and overtopping devices. Proceedings of the 3rd International Conference on Renewable Energies Offshore (RENEW-2018). Lisbon, Portugal2018. 